\title{
War-Related Trauma and Symptoms of Posttraumatic Stress Disorder Among Adult Kosovar Refugees
}

\author{
Amy L. Ai, ${ }^{1,3}$ Christopher Peterson, ${ }^{2}$ and David Ubelhor ${ }^{1}$
}

\begin{abstract}
Since 1999, almost 16,000 Kosovar refugees have entered the United States. Few studies have investigated trauma and symptoms of posttraumatic stress disorder (PTSD) in this population. We conducted a caseworker-assisted survey of 129 Kosovar refugees (aged 18 to 79 years, 55\% male). Of these individuals, $78(60.5 \%)$ showed the likely presence of PTSD. The mean number of war-related traumatic events reported was $15(S D=4.5)$. Higher PTSD scores were associated with more traumatic events and female gender.
\end{abstract}

KEY WORDS: war trauma; posttraumatic stress disorder; Kosovar refugee; gender difference; proximate time to war.

Since 1999, almost 16,000 Kosovar refugees have resettled the United States (Vialet, 2000). Fresh from the recent war, many have been described as traumatized. Few studies have investigated how trauma has impacted this population in terms of producing symptoms of posttraumatic stress disorder (PTSD). We studied Kosovar refugees settled in Michigan and Washington, two states with very different cultural and ecological contexts. Because Michigan has the second largest Albanian American population in the United States, many Michigan refugees had relatives or friends in the state, whereas few Washington refugees knew anyone in the state prior to resettlement.

The present study used a survey procedure to address (a) the frequency of war-related trauma, (b) the prevalence and patterning of PTSD symptoms, and (c) the association of PTSD symptoms with the frequency of trauma and demographic characteristics. On the basis of previous studies of recent war refugees from other Yugoslav regions (Favaro, Majorani, Colombo, \& Santonastaso, 1999;

\footnotetext{
${ }^{1}$ School of Social Work, University of Washington, Seattle, Washington.

${ }^{2}$ Department of Psychology, University of Michigan, Ann Arbor, Michigan.

${ }^{3}$ To whom correspondence should be addressed at School of Social Work, 4101 15th Ave, University of Washington, NE, Seattle, Washington 98105-6299; e-mail: amyai@umich.edu; amyai@u.washington.edu.
}

Mollica et al., 1999; Thulesius \& Hakansson, 1999; Weine et al., 1995), we expected to find a high prevalence of PTSD symptoms. We were also interested in differences between the two samples, and we administered a measure of social support to see if it accounted for differences that might emerge.

Method

\section{Participants and Procedure}

Before the study began, the goals and the procedures were explained to representatives and caseworkers at agencies involved with resettling Kosovar refugees. Five refugee resettlement agencies associated with local churches in south-central Michigan and the World Relief organization in Washington agreed to participate.

Following an agency's advice, we used a caseworkerassisted recruiting strategy to protect privacy and promote participation. The Imam of the Albanian Islamic Center in Detroit wrote a letter in Albanian in support of the proposed study, which was included with our package to refugees. Bilingual caseworkers directly contacted or phoned Kosovar refugees, especially the heads of clans, requesting participation. Caseworkers met with potential research participants to explain the study. Then they 
distributed the contact letter, the consent form, and the measures. Illiterate refugees were assisted with questionnaires by caseworkers. Each refugee used a provided stamped envelope to return the questionnaire. As a reminder, follow-up thank-you notes were sent 2 weeks after distribution of questionnaires. Approximately $90 \%$ of the individuals approached took questionnaires, and approximately $90 \%$ of these individuals returned them. Through the participating social service agencies, refugees who returned questionnaires were each paid $\$ 10$, as were their caseworkers.

Our research participants resettled in the United States between April and October 1999. Between December and May 2000, recruitment by cooperating social service agency caseworkers occurred. We received questionnaires from 139 refugees. Data from 10 research participants were excluded. One respondent was only 14 years old, and nine respondents answered too few questions. Of the valid 129 cases, 54 (42\%) were from Michigan, and $75(58 \%)$ were from Washington. There were $71(55 \%)$ men and $58(45 \%)$ women. Average age was 35 years $(S D=14)$, ranging from 18 to 79 . Average years of education was 11 years $(S D=4)$, ranging from 0 to 17 . The majority of participants identified themselves as Albanian ( $n=127,98 \%)$ and Muslim $(n=124,96 \%)$. Most were married and had resettled with their spouse ( $n=86,67 \%$ ). They came from a variety of occupational backgrounds. There were no differences between the two samples with respect to these demographic characteristics or indeed any of the measures. We therefore present findings collapsed across this contrast.

\section{Measures}

An Albanian scholar at the Massachusetts Institute of Technology completed translation of the contact letter, the consent form, and the survey instruments from English to Albanian. Because of the difficulty in finding qualified translators, we did not undertake formal back translation. However, the translation was independently checked and approved by a professional Albanian interpreter working for the Federal government.

The questionnaire asked about (a) demographics, (b) war-related traumatic events, (c) PTSD symptoms, and (d) social support. We also measured several other constructs not relevant here.

We measured war-related trauma with a shortened version of the Communal Traumatic Events Inventory developed by Weine et al. (1995) for studying Bosnian refugees. Because of advice received from caseworkers, we included only events most likely to have occurred. Respondents indicated with a yes or no answer whether they had experienced each of 24 war-related traumatic events during their transition from Kosovo to the United States.

Social support was measured with the Tangible, Emotional, and Informational Assistance from Others Scale (Krause, 1999). This measure contains 10 items tapping different aspects of social support. Respondents indicated on 4-point scales $(1=$ never; $2=$ once in a while; $3=$ fairly often; and $4=$ very often) how often they had received the type of social support since their arrival in the United States. Although this measure was designed to yield subscale scores, these proved substantially intercorrelated, and we computed an overall social support score by averaging responses to the 10 items $(\alpha=.88)$. The average level of social support was $3.56(S D=.84)$.

The PTSD Symptom Scale was used to ascertain symptoms (Foa, Riggs, Dancu, \& Rothbaum, 1993). This self-report questionnaire has excellent convergent validity with structured interviews. Respondents indicated on 4-point scales the degree to which they had experienced each of 17 symptoms in the past week $(0=$ not at all; $1=$ once a week; $2=2$ to 4 times a week or "half the time"; and $3=5$ or more times a week or "almost always"). Items reflected each of the three symptom clustersreexperiencing trauma (5 items), avoiding trauma reminders ( 7 items), and experiencing arousal (5 items)specified in the Diagnostic and Statistical Manual for Mental Disorders (DSM; American Psychiatric Association, 1994). We calculated an overall severity score by summing responses to all items, and we computed scores within each symptom cluster by summing the appropriate items. In the present sample, the alpha estimates of internal consistency were .93 for overall severity $(M=22.5$, $S D=11.5), .87$ for reexperiencing $(M=6.3, S D=3.7)$, .75 for avoidance $(M=7.2, S D=3.9)$, and .86 for arousal $(M=9.0, S D=5.3)$.

\section{Results}

Research participants experienced a high degree of trauma (Table 1). The mean number of events reported (of 24 possible) was $15(S D=4.5)$. More than $90 \%$ of the participants reported 10 or more events. Overall frequency of trauma was unrelated to any of the demographic variables.

The results showed that the sample was highly distressed. We classified a symptom as present for a given individual if he or she reported a value of 2 or greater on the corresponding item. This criterion was used in Weine et al.'s report (1995) to indicate the highest severity rating level for symptoms experienced by Bosnian refugees. As shown in Table 2, eight PTSD symptoms were present most frequently, as reported by more than half of the 
Table 1. Frequencies of Traumatic Events

\begin{tabular}{lr}
\hline \multicolumn{1}{c}{ Event } & $N(\%)$ \\
\hline Evacuated from town & $120(93 \%)$ \\
Refugee camp & $119(92 \%)$ \\
Shortage of medicine & $114(88 \%)$ \\
Lack of food & $110(85 \%)$ \\
Stolen possessions & $108(84 \%)$ \\
Without shelter & $106(82 \%)$ \\
Shortage of clothing & $104(81 \%)$ \\
Separated from loved ones & $104(81 \%)$ \\
Forced marches & $102(79 \%)$ \\
Solitary confinement & $102(79 \%)$ \\
Lost property & $97(75 \%)$ \\
Concentration camp & $92(71 \%)$ \\
Family beaten & $86(67 \%)$ \\
Ill health & $76(59 \%)$ \\
Death of family member & $76(59 \%)$ \\
Witnessed violence & $64(50 \%)$ \\
Kidnapped & $61(47 \%)$ \\
Loved ones disappeared & $60(47 \%)$ \\
Destruction - personal property & $59(46 \%)$ \\
Witnessed torture & $54(42 \%)$ \\
Beaten & $49(38 \%)$ \\
Physical injury & $39(30 \%)$ \\
Witnessed death & $26(20 \%)$ \\
Sexual acts & $4(3 \%)$ \\
\hline
\end{tabular}

sample. In all, $78(60.5 \%)$ of the respondents showed a pattern consistent with symptom criteria for PTSD; Criteria $\mathrm{A} 2$ and $\mathrm{F}$ (Functioning) were not assessed. All together, 96 individuals $(74.4 \%)$ reported at least one reexperiencing symptom, 58 individuals (45\%) reported three or more avoidance symptoms, and 95 individuals (73.6\%) reported two or more arousal symptoms.

The final purpose of our study was to examine correlations between PTSD severity scores, trauma level, social support, and demographics. Correlating with higher PTSD severity scores were being female $(r=.25, p<.01)$ and being married with spouse present (vs. other types of marital status; $r=.19, p<.05)$. However, only women were more likely to meet symptom criteria, $\Pi^{2}(1, N=129)=$ 5.33, $p<.05$. Unlike Weine et al.'s study on Bosnian refugees (1995), in this Kosovar sample, people who met symptom criteria did not differ in age, on average, from

Table 2. Frequencies of Eight Most Common PTSD Symptoms

\begin{tabular}{lc}
\hline \multicolumn{1}{c}{ Symptoms } & $N(\%)$ \\
\hline Sleep disturbance & $85(66 \%)$ \\
Upset when reminded of the trauma & $78(61 \%)$ \\
Flashbacks & $76(59 \%)$ \\
Physical reactivity to war reminders & $75(59 \%)$ \\
Irritability & $74(57 \%)$ \\
Intrusive memories & $67(52 \%)$ \\
Avoiding thoughts of the war & $67(52 \%)$ \\
Avoiding war reminders & $66(51 \%)$ \\
Increased startle response & $66(51 \%)$ \\
\hline
\end{tabular}

those who did not meet symptom criteria, $t(126)<1$. Trauma level (count of events) was not related to any sociodemographic variables. Trauma level correlated positively with PTSD severity scores $(r=.39, p<.01)$ as well as with the likelihood of meeting all symptom criteria $(r=.29, p<.01)$. Social support was unrelated to PTSD severity $(r=.12, n s)$. The same patterns of results held when we looked separately at PTSD scores for the three symptom clusters.

\section{Discussion}

The social service agencies with which we worked had resettled other refugee populations, but caseworkers told us that they had never encountered individuals as traumatized as the Kosovar refugees. Asian and African refugees, unlike their Kosovar counterparts, had usually traveled or stayed in refugee camps for longer periods of time before resettling, and some had worked in other countries. They suffered mainly from economic hardship and culture shock upon their arrival in the United States. In contrast, most Kosovar refugees came directly from Kosovo or short-term refugee camps. All had fresh experiences of war at the time the survey was conducted. It is not surprising that so many reported symptoms of distress with an overall high pattern of three-subgroup PTSD symptoms, a pattern that differs from the double-high pattern (reexperiencing and avoidance) that was reported by Weine et al. (1995) and Favaro et al. (1999). Although the pattern may be attributable to a cultural difference, an alternative explanation could again be the close proximity in time of the assessment to the Kosovar conflict.

Previous studies of refugees from the former Yugoslavia have found varying prevalence rates of PTSD. Apart from assessment differences, one of the likely reasons for this variation is the timing of evaluation. Studies conducted after longer periods of time away from war find lower rates of PTSD. Our sample of Kosovars was most similar to the adult Bosnians studied by Weine et al. (1995). Both groups were studied immediately upon resettlement from a war zone and had high rates of apparent PTSD. In fact, if we had used the same algorithm (value of 1 or greater) used by Weine et al. for scoring a symptom as present instead of a more conservative rule (value of 2 or greater), $78 \%$ of our sample would have met the criteria, which is not far below the rate $(93 \%)$ Weine et al. obtained for the adults in their study. We did not use face-to-face interviews as did Weine et al. (1995), and questionnaire measures have been criticized for overestimating psychopathology (Coyne \& Kagee, 2000). Nonetheless, the agreement in results between our study and the previous one supports the validity of our procedures. 
The lack of difference between our two samples adds to the potential generality of our conclusions.

Unlike other investigations of recent refugees from the former Yugoslavia (Favaro et al., 1999; Mollica et al., 1999; Thulesius \& Hakansson, 1999; Weine et al., 1995), our study found a gender difference in PTSD severity scores and the likelihood of PTSD diagnosis. Further investigation into the different war experiences of men and women and how these might result in more severe symptoms for women is warranted. Unlike previous investigators, we found that age was related to neither higher PTSD severity scores nor the likelihood of diagnosis.

Despite the contributions of the present study, limitations should be acknowledged. First, the cross-sectional nature of the study does not permit causal conclusions. Second, the study used questionnaires rather than diagnostic interviews capturing the full DSM diagnosis of PTSD. Third, language and ethnocultural barriers may have inadvertently affected instrument validity. Finally, findings based on convenience samples need to be replicated in probability samples of this population.

In conclusion, the potential cultural barrier of treating Kosovar refugees lies in their tradition of seeking help from clans rather than from professional providers. Research has demonstrated the long-term benefit of early treatment of war-related PTSD among other refugee groups from the former Yugoslavia (Drozdek, 1997). Nonetheless, anticipated resistance to treatment on the part of some refugees may require different types of assistance, like a culturally sensitive family approach (Weine, Kulenovic, Pavkovic, \& Gibbons, 1998).

\section{Acknowledgments}

This research was done while Amy Ai was supported by the National Institute on Mental Health Grant, R24 MH56599, the National Center for Complementary and Alternative Medicine Grant, 1 P50 AT00011, and the John Templeton Foundation. Christopher Peterson was supported by 1 P50 HL061202 01 and by the Values in Action Institute. Funds to support some of this research were provided by the Office of Vice President for Research, University of Michigan, The opinions expressed in this article are those of the authors and do not necessarily reflect the views of these funders. The authors gratefully acknowledge the contributions of Minh Phung Ngo, Rudi Gjoni, Rafaela Prifti, Meri Traska, Reverend Nile Harper, Imam Vabhhi Ismael, Reverend Saundra Richardson, Sandi Rosso, Rachel Yoskowitz, Terry Walsh, World Relief (Seattle), Catholic Archdiocese of Detroit, Episcopal Diocese of Detroit, Albanian Islamic Center of Detroit, Jewish Family Service of Southfield, and Catholic Social System Refugee Services of Lansing.

\section{References}

American Psychiatric Association. (1994). Diagnostic and statistical manual of mental disorders (4th ed.). Washington, DC: Author.

Coyne, J. C., \& Kagee, A. (2000). Mental health among Bosnian refugees. Journal of the American Medical Association, 283, 55.

Drozdek, B. (1997). Follow-up study of concentration camp survivors from Bosnia-Herzegovina: Three years later. Journal of Nervous and Mental Disease, 185, 690-694.

Favaro, A., Majorani, M., Colombo, G., \& Santonastaso, P. (1999). Traumatic experiences, posttraumatic stress disorder, and dissociative symptoms in a group of refugees from former Yugoslavia. The Journal of Nervous and Mental Disease, 187, 306-308.

Foa, E. B., Riggs, D. S., Dancu, C. V., \& Rothbaum, B. O. (1993). Reliability and validity of a brief instrument for assessing posttraumatic stress disorder. Journal of Traumatic Stress, 6, 459-473.

Krause, N. (1999). Assessing change in social support during late life. Research on Aging, 21, 539-569.

Mollica, R. F., McInnes, K., Sarajli'c, N., Lavelle, J., Sarajlic, I., \& Massagli, M. P. (1999). Disability associated with psychiatric comorbidity and health status in Bosnian refugees living in Croatia. Journal of the American Medical Association, 282, 433439.

Thulesius, H., \& Hakansson, A. (1999). Screening for posttraumatic stress disorder symptoms among Bosnian refugees. Journal of Traumatic Stress, 12, 167-174.

Vialet, J. (2000). U.S. Refugee admissions and resettlement policy: Facts and issues. Migration World, 28, 14-18.

Weine, S. M., Becker, D. F., McGlashan, T. H., Laub, D., Lazrove, S., Vojvoda, D., \& Hyman, L. (1995). Psychiatric consequences of "ethnic cleansing": Clinical assessments and trauma testimonies of newly resettled Bosnian refugees. American Journal of Psychiatry, $152,536-541$.

Weine, S. M., Kulenovic, A. D., Pavkovic, I., \& Gibbons, R. (1998). Testimony psychotherapy in Bosnian refugees: A pilot study American Journal of Psychiatry, 155, 1720-1726. 